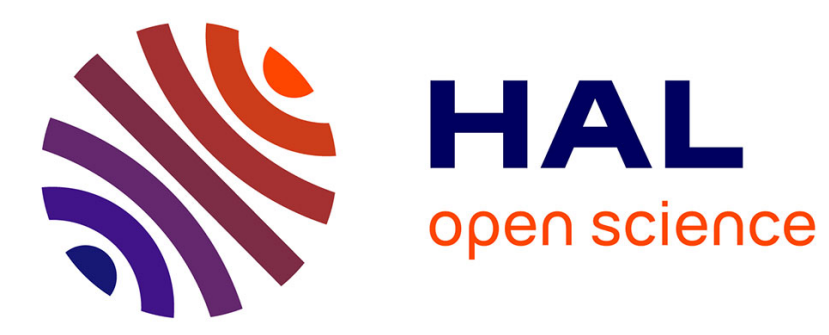

\title{
Comparison of OGO 6 measured thermospheric temperatures with the MSIS-86 empirical model
}

\author{
A.E. Hedin, Gérard Thuillier
}

\section{To cite this version:}

A.E. Hedin, Gérard Thuillier. Comparison of OGO 6 measured thermospheric temperatures with the MSIS-86 empirical model. Journal of Geophysical Research Space Physics, 1988, 93 (A6), pp.59655971. 10.1029/JA093iA06p05965 . insu-01627449

\section{HAL Id: insu-01627449 \\ https://hal-insu.archives-ouvertes.fr/insu-01627449}

Submitted on 2 Mar 2021

HAL is a multi-disciplinary open access archive for the deposit and dissemination of scientific research documents, whether they are published or not. The documents may come from teaching and research institutions in France or abroad, or from public or private research centers.
L'archive ouverte pluridisciplinaire HAL, est destinée au dépôt et à la diffusion de documents scientifiques de niveau recherche, publiés ou non, émanant des établissements d'enseignement et de recherche français ou étrangers, des laboratoires publics ou privés. 


\title{
Comparison of OGO 6 Measured Thermospheric Temperatures With the MSIS-86 Empirical Model
}

\author{
A. E. HEDIN \\ Laboratory for Atmospheres, NASA Goddard Space Flight Center, Greenbelt, Maryland \\ G. THUILLIER
}

Service d'Aéronomie du Centre National de la Recherche Scientifique, Verrières-le-Buisson, France

\begin{abstract}
The thermospheric temperatures measured by the Fabry-Perod interferometer on the OGO 6 satellite are found to be reasonably represented by the mass spectrometer/incoherent scatter 1986 (MSIS-86) empirical model except for two anomalies, one in the South Atlantic and the other near noon local time. These anomalies are likely due to measurement problems. The OGO 6 temperature data were not used in the generation of the MSIS models, so this is an independent comparison of measured and model temperatures. The measurements were made primarily during daytime at mid to low latitudes and throughout the day at high latitudes. On average, the measured temperatures are $16 \mathrm{~K}$ below the MSIS-86 model temperatures. Latitude gradients during solstices as well as for the yearly average are well represented by the model, as are high-latitude longitudinal and magnetic activity variations.
\end{abstract}

\section{INTRODUCTION}

Measurements of thermospheric temperatures from ground stations and satellites provide valuable complementary information needed to understand the variability and physics of the thermosphere. Ground stations can provide a long time series of measurements to study solar activity and seasonal variations which complement the global coverage provided by occasional satellites. The major methods of taking groundbased temperature measurements use optical (Fabry-Perot interferometer [Shepherd, 1972; Hernandez, 1986]) and radio (incoherent scatter [Evans, 1969]) techniques. The methods of determining temperature from a satellite have included the baflle-modulated mass spectrometer technique [Spencer et al., 1973, 1981], use of the Fabry-Perot interferometer [Blamont and Luton, 1972; Hays et al., 1981], inference from $\mathrm{N}_{2}$ densities [Hedin et al., 1974], and inference from total densities [Jacchia, 1965, 1971, 1977].

The first global models of the thermosphere were based on total densities determined from satellite drag, and temperature variations were inferred from density variations [Jacchia, 1965]. Early measurements of temperature by the incoherent scatter technique [Carru et al., 1967; Nisbet, 1967], however, showed significant differences in the diurnal and seasonal variation as compared to satellite drag models. Temperatures inferred from $\mathrm{N}_{2}$ densities [Hedin et al., 1974] were found to be similar to temperatures measured by incoherent scatter and led to the mass spectrometer/incoherent scatter (MSIS) series of models [Hedin et al., 1977; Hedin, 1983, 1987], which based temperature on $\mathrm{N}_{2}$ density, incoherent scatter, and later also the baffle-modulated mass spectrometer technique.

Initial comparisons of nighttime thermospheric temperatures measured by ground-based Fabry-Perot interferometers with temperatures determined using empirical models and incoherent scatter showed reasonable agreement [Biondi and Feibelman, 1968; Hays et al., 1970; Cogger et al., 1970; Hernandez et al., 1975]. Examination of line shapes and theoretical

Copyright 1988 by the American Geophysical Union.

Paper number 7A9443.

0148-0227/88/007A-9443\$02.00 estimates indicated that $O\left({ }^{1} D\right)$ should be in thermal equilibrium with the neutral atmosphere before emission of the $6300-\AA$ red line [Biondi and Feibelman, 1968]. However, a systematic comparison by Hernandez [1982] of data from Fritz Peak with predictions of several models, including the MSIS-77 model [Hedin et al., 1977], showed that the measured temperatures were generally higher than those of the models by about $100 \mathrm{~K}$, particularly at low solar activity. The MSIS-77 temperatures at mid-latitudes are somewhat higher than the MSIS-86 temperatures [Hedin, 1987] on average and are within $50 \mathrm{~K}$ of MSIS- 86 temperatures under a wide variety of conditions. Measured temperatures that are higher than model temperatures have also been found for more limited data samples at other observation sites [Feibelman et al., 1972; Sipler et al., 1983; Biondi and Meriwether, 1985; Yagi and Dyson, 1985]. Thus there may be a systematic difference between the optical technique and the other methods of temperature measurement under certain conditions. Recently, Yee [1988] has calculated the nonthermal distribution of the $O\left({ }^{1} D\right)$ atoms at night and concludes that the measured temperature of the red line emission would be higher than the ambient temperature by about $100 \mathrm{~K}$, but this same conclusion does not necessarily apply to daytime, when the sources of $O\left({ }^{1} D\right)$ are different, In addition, temperature gradients near the emission peak may bias the altitude assigned to the measured temperature [McCormac et al., 1987].

The OGO 6 satellite was launched in an elliptical (400-1100 km) polar orbit in June 1969. It carried a spherical FabryPerot interferometer, which provided data until a spacecraft problem occurred in August 1970, for determining thermospheric temperatures from the $6300-\AA$ emission at $F$ region heights [Blamont and Luton, 1972; Blamont et al., 1974].

Data were generally obtained during daytime at all latitudes and also during nighttime at high latitudes because of the line intensity increase in these regions. The typical statistical error of a single data point is $50 \mathrm{~K}$. Data are generally obtained every $2^{\circ}$ of latitude, but as the atmosphere is observed tangentially, an integration along the line of view is made over $1500-2000 \mathrm{~km}$. The altitude resolution, which varies with spacecraft altitude, is $20 \mathrm{~km}$ at perigee. 


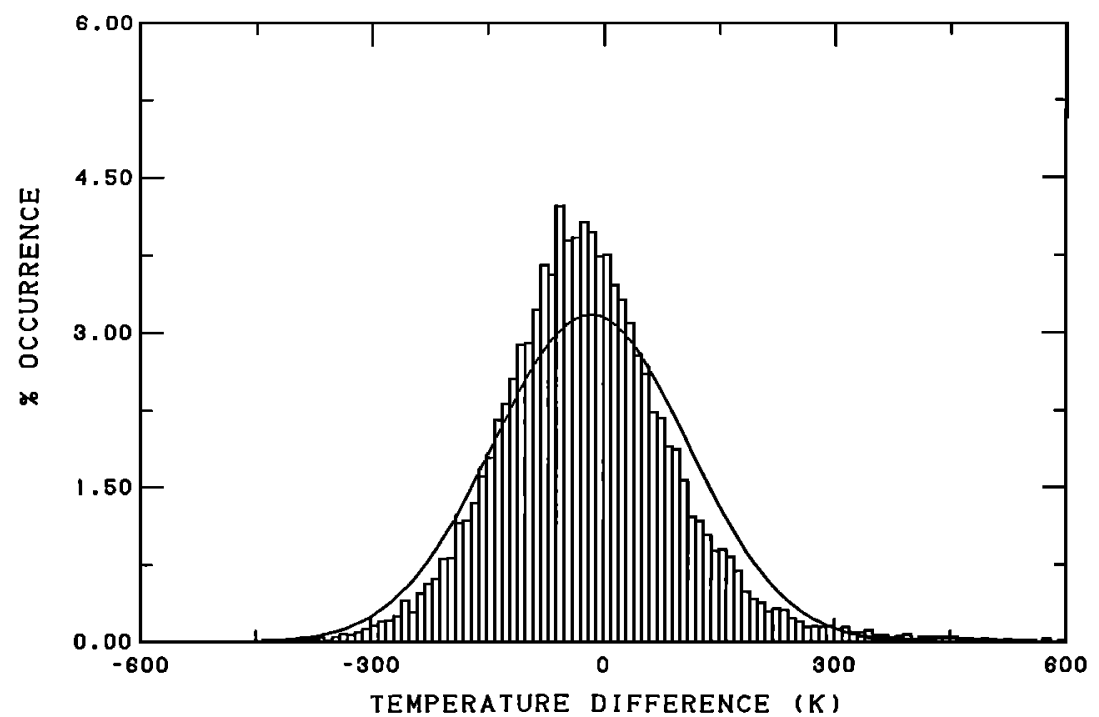

Fig. 1. Histogram showing percent occurrence of OGO 6 measured minus MSIS-86 model temperature data for quiet magnetic conditions $(A P<10)$. The solid curve shows the normal distribution based on the average difference of $-16 \mathrm{~K}$ and the standard deviation of $126 \mathrm{~K}$.

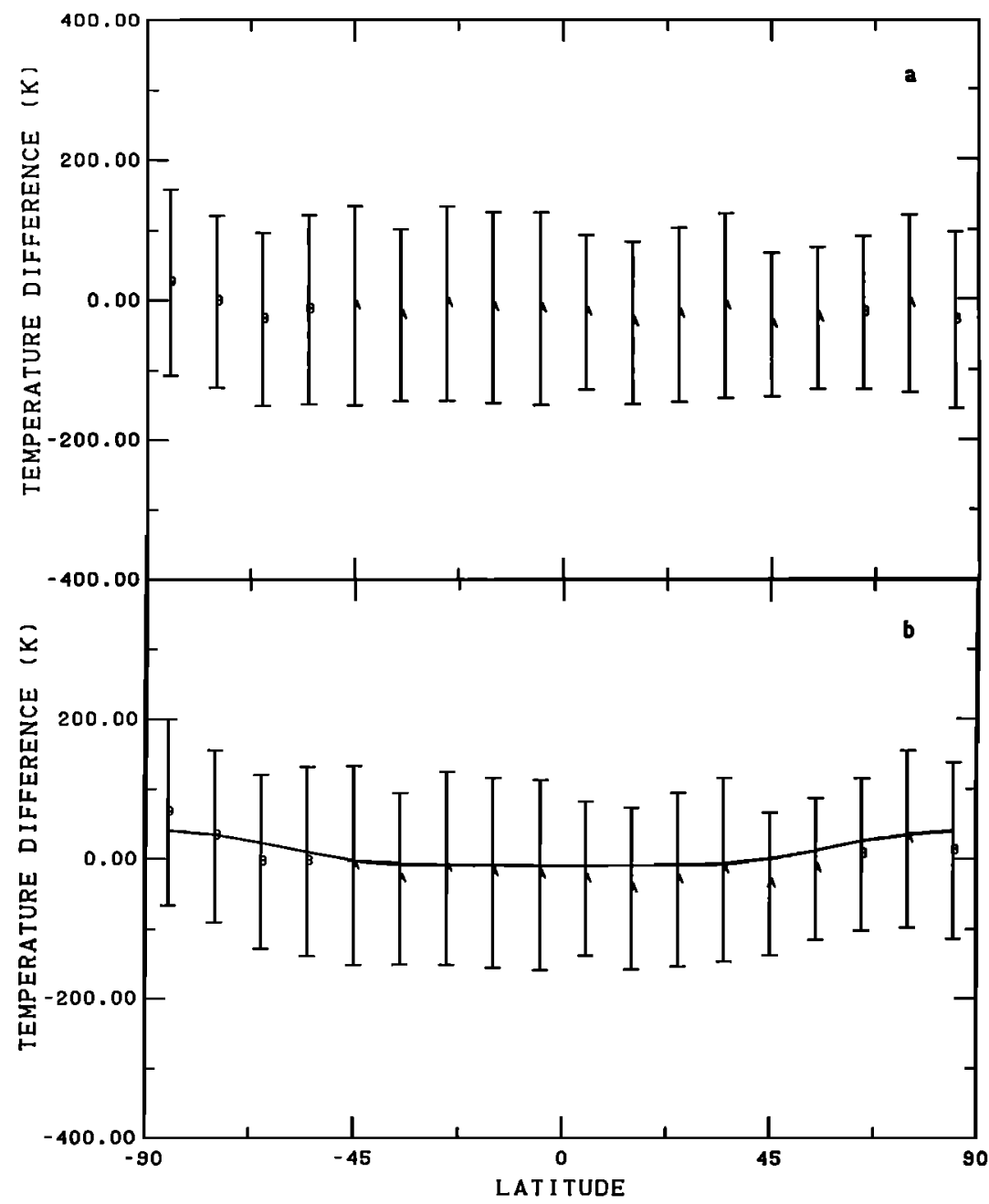

Fig. 2. (a) Measured minus MSIS-86 model temperatures averaged in $10^{\circ}$ latitude bins versus latitude for quiet magnetic activity conditions. Bars show standard deviation of the scatter within each bin, with 250-1000 points per bin. (b) Measured minus MSIS- 86 model temperatures without time independent terms averaged in $10^{\circ}$ latitude bins versus latitude and corresponding model prediction averages for the measurement conditions connected by straight lines. Standard deviation is as described for Figure $2 a$. 


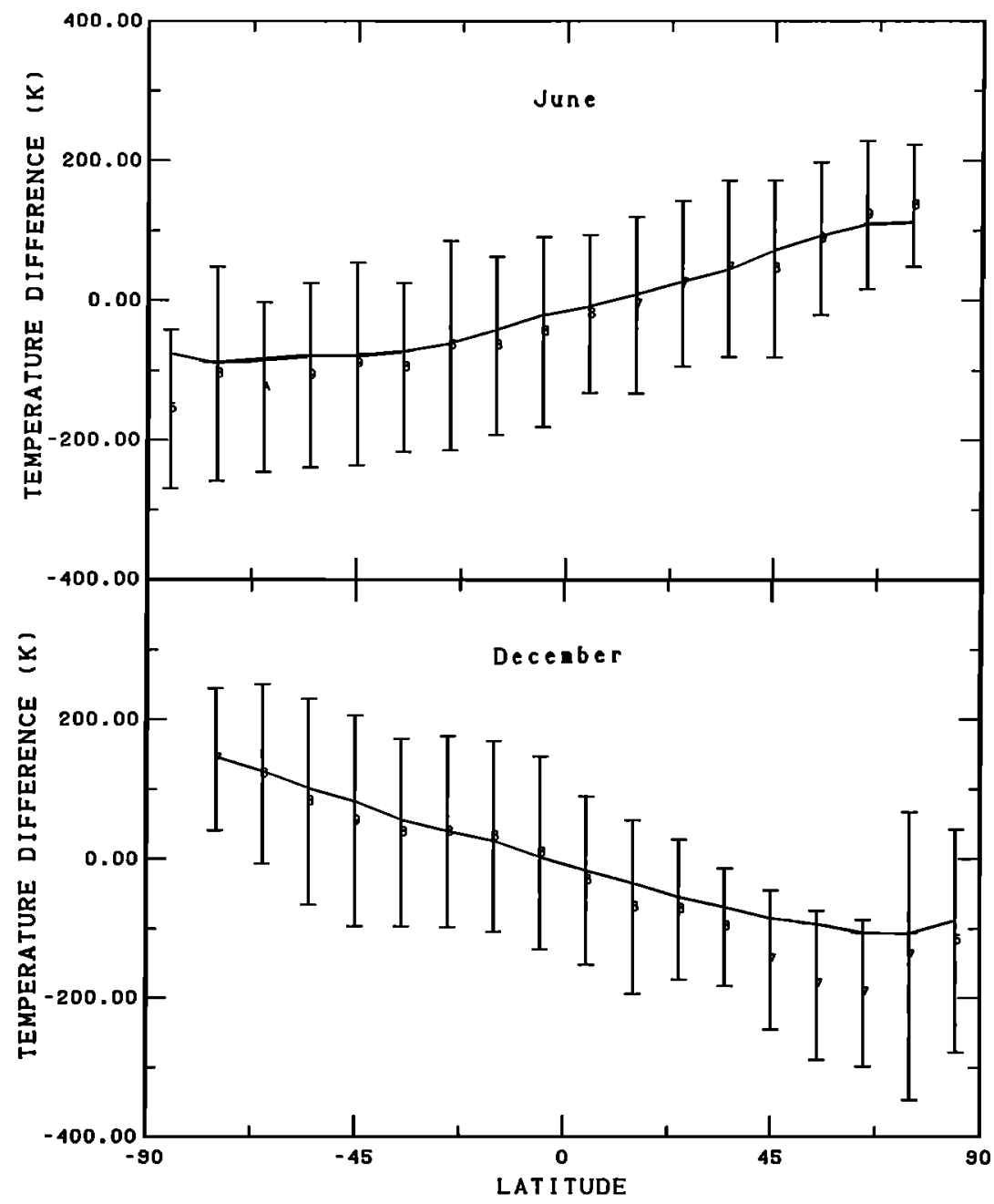

Fig. 3. Measured minus MSIS-86 model temperatures without time independent and yearly variation terms averaged in $10^{\circ}$ latitude bins versus latitude for quiet magnetic activity conditions and corresponding model predictions (connected by straight lines) for June solstice (upper panel) and December solstice (lower panel).

Early comparisons with Jacchia drag models showed that measured temperatures increased toward the poles and had larger seasonal variations and a later diurnal maximum than temperatures given by the drag models. There were originally 238,000 data points. Their behavior has been studied as a function of the measurement conditions, such as minimum altitude of the line of view, line and background intensities, threshold of the detector, and South Atlantic magnetic anomaly. There was no normalization to ground-based or other data. Selection criteria based on these considerations reduced the original number of measurements to 47,331 , which were suitably distributed as a function of latitude, day, and local time for the purpose of modeling. They have been incorporated in three empirical models [Thuillier et al., 1977a, b, 1980]. More severe selection criteria would have provided a poor data distribution, for the purposes of the original modeling work, with respect to latitude, day, and local time, but they may be needed, as the comparisons with the model in this paper suggest.

The OGO 6 temperature data were not incorporated in the MSIS models. This paper presents the results of a comparison of the OGO 6 optical Fabry-Perot temperatures with the MSIS-86 model temperatures in order to provide additional insight into the question of absolute thermospheric temperatures and variations.

\section{COMPaRISON AND Discussion}

The overall comparison of measured to model temperatures is shown in Figure 1 in terms of a histogram of the deviations from the MSIS-86 temperatures [Hedin, 1987]. The measured temperatures are on average only $16 \mathrm{~K}$ below the model temperatures but have a large standard deviation of $126 \mathrm{~K}$. The data minus model residuals have a long tail toward positive values. Further examination of the residuals, described below, indicates that gross geophysical variations are very similar for the measured and model temperatures except for two obvious anomalies. However, there remains an inherent scatter in the residuals of the order of $100 \mathrm{~K}$ which may be due, in part, to waves and local heating not resolved by the limited spatial and temporal resolution of the model. The existence of large point to point variations, particularly at high latitudes, was noted by Blamont and Luton [1972].

The measured minus MSIS-86 model temperature differences are shown as a function of latitude in Figure $2 a$ using $10^{\circ}$ averages. While the scatter within each bin is over $100 \mathrm{~K}$, the scatter between bin averages is only $15 \mathrm{~K}$. In order to emphasize the average variation of temperature with latitude, Figure $2 b$ shows the differences between the measured and the model temperatures with the time independent terms (i.e., dependent on latitude, but not on day of year or time of day) of 


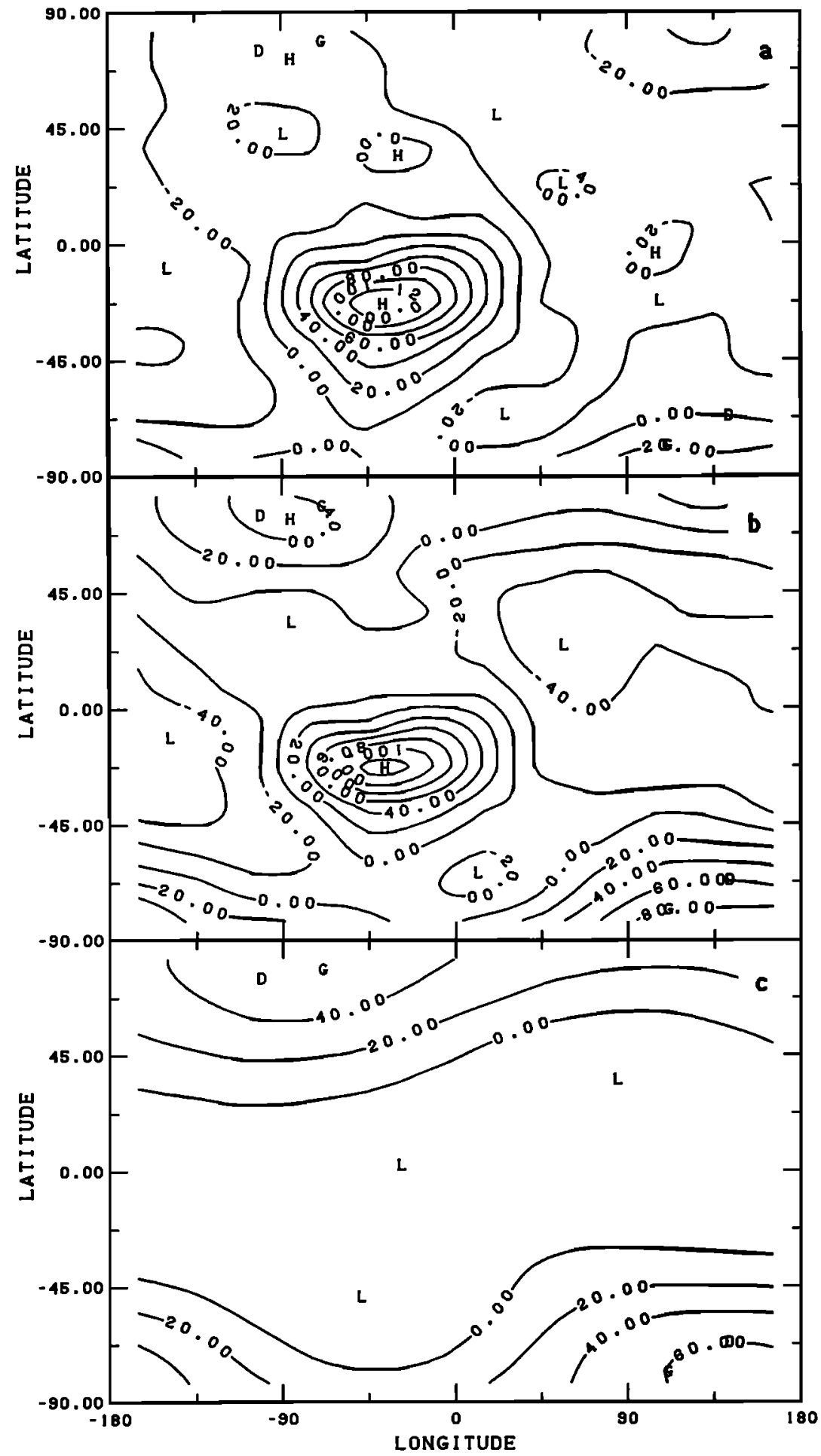

Fig. 4. (a) Contours of measured minus MSIS-86 model temperatures in longitude/latitude coordinates using $30^{\circ}$ longitude by $15^{\circ}$ latitude bins for quiet magnetic activity conditions. (b) Same as in Figure $4 a$ but without longitude terms of the model. (c) Model prediction of longitude variations.

the model omitted. The similar comparison of the full model calculated for the data conditions to the model without the time independent terms provides the corresponding model predictions of the average latitude variation for the OGO 6 data. The data on average agree quite well with the $\sim 40-\mathrm{K}$ increase from equator to poles predicted by the model.

The agreement between data and model for the seasonal temperature variations is shown in Figure 3, where model predictions of the latitudinal variation during the June and
December solstices are compared with data minus model predictions with the time independent and yearly variation terms omitted from the model. The most serious disagreement is at moderately high latitudes during northern winter. The data here are largely from local times around noon and probably reflect a data anomaly around noon to be discussed later. Thuillier et al. [1977a] showed that there was general agreement with incoherent scatter for the seasonal variations in OGO 6 temperatures. These seasonal temperature variations 


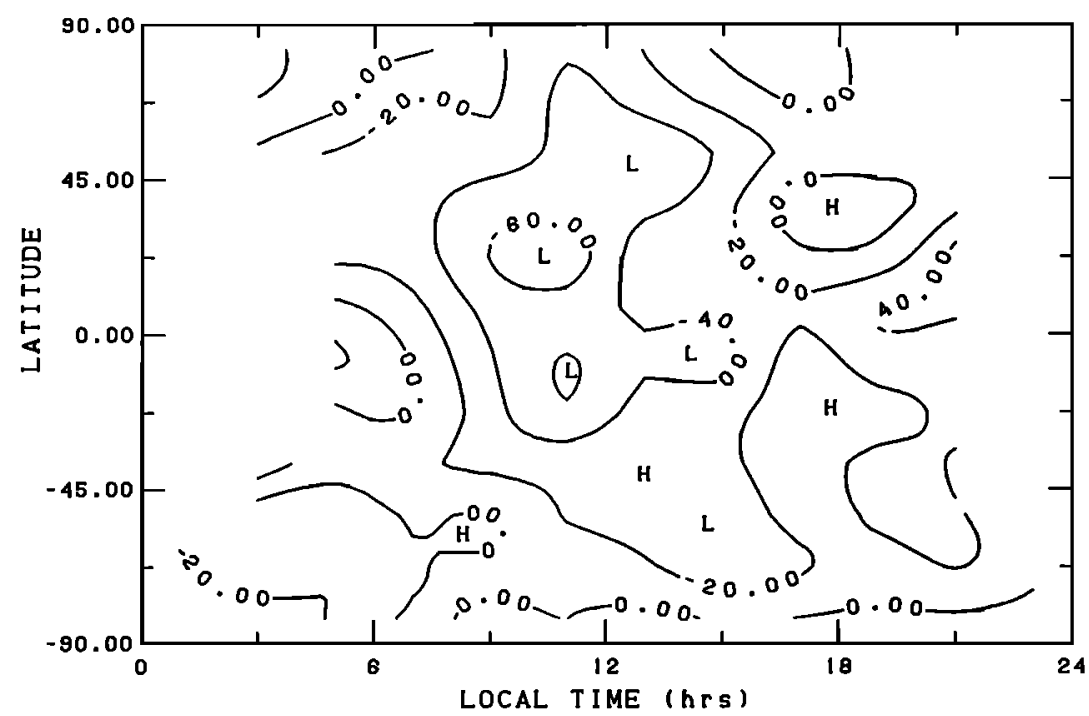

Fig. 5. Contours of measured minus MSIS-86 model temperatures in local time/latitude coordinates using 2-hour local time by $15^{\circ}$ latitude bins for quiet magnetic activity conditions.

are much larger than in early drag models [Jacchia 1965, 1971] and lead to a global maximum at much higher summer latitudes [Blamont et al., 1974] than the sub-solar point location predicted by drag models.
The data minus model differences are shown in Figure 4 as a function of latitude and longitude. Also shown are the model predictions for the longitudinal variations, originally estimated from $\mathrm{N}_{2}$ density variations [Hedin et al., 1979], and the

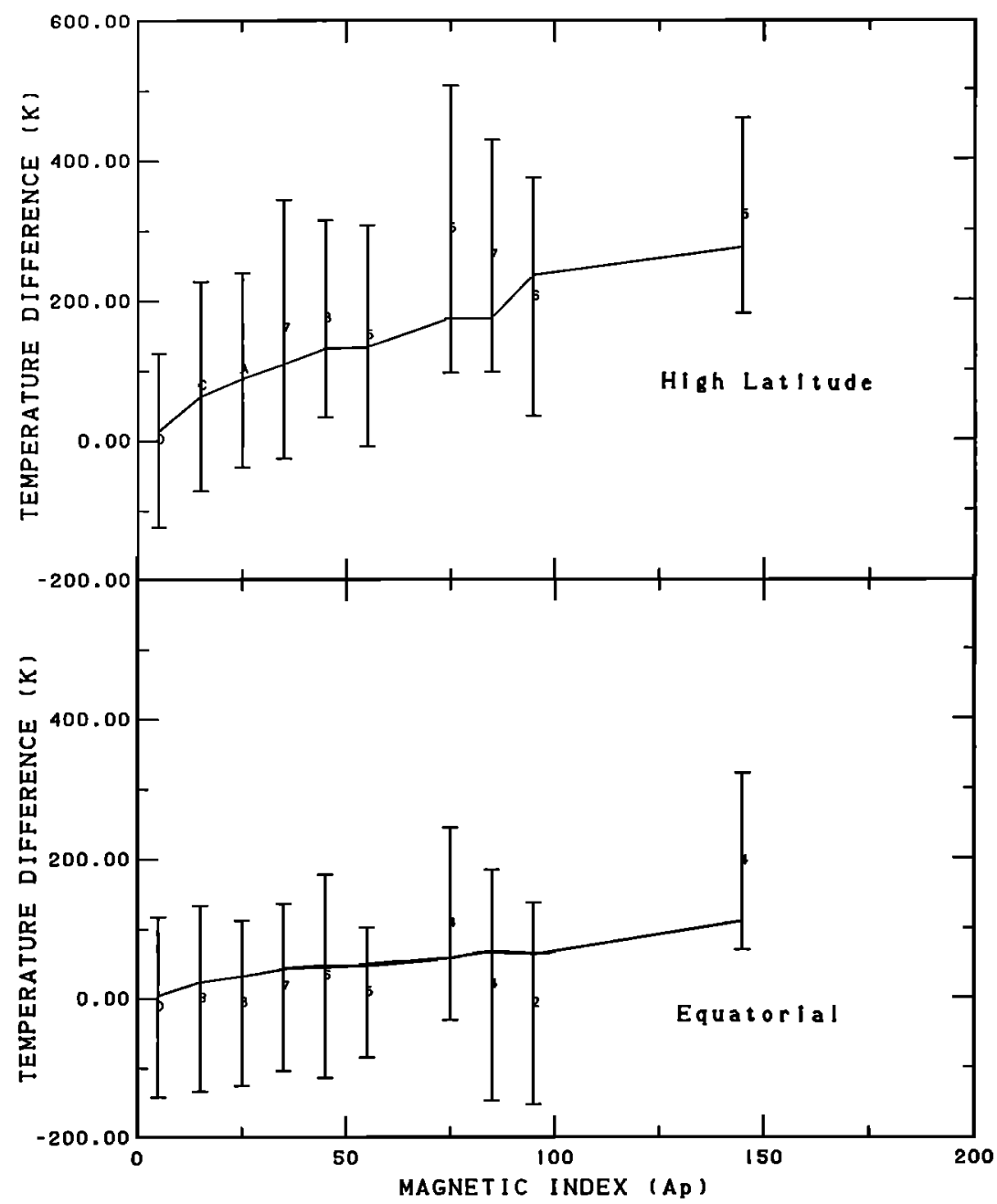

Fig. 6. Measured minus MSIS-86 model temperatures, with model magnetic activity terms omitted, versus magnetic activity $(A P)$ averaged in 10-unit intervals and corresponding model predictions (connected by straight lines) for latitudes poleward of $60^{\circ}$ (upper panel) and equatorward of $30^{\circ}$ (lower panel). 


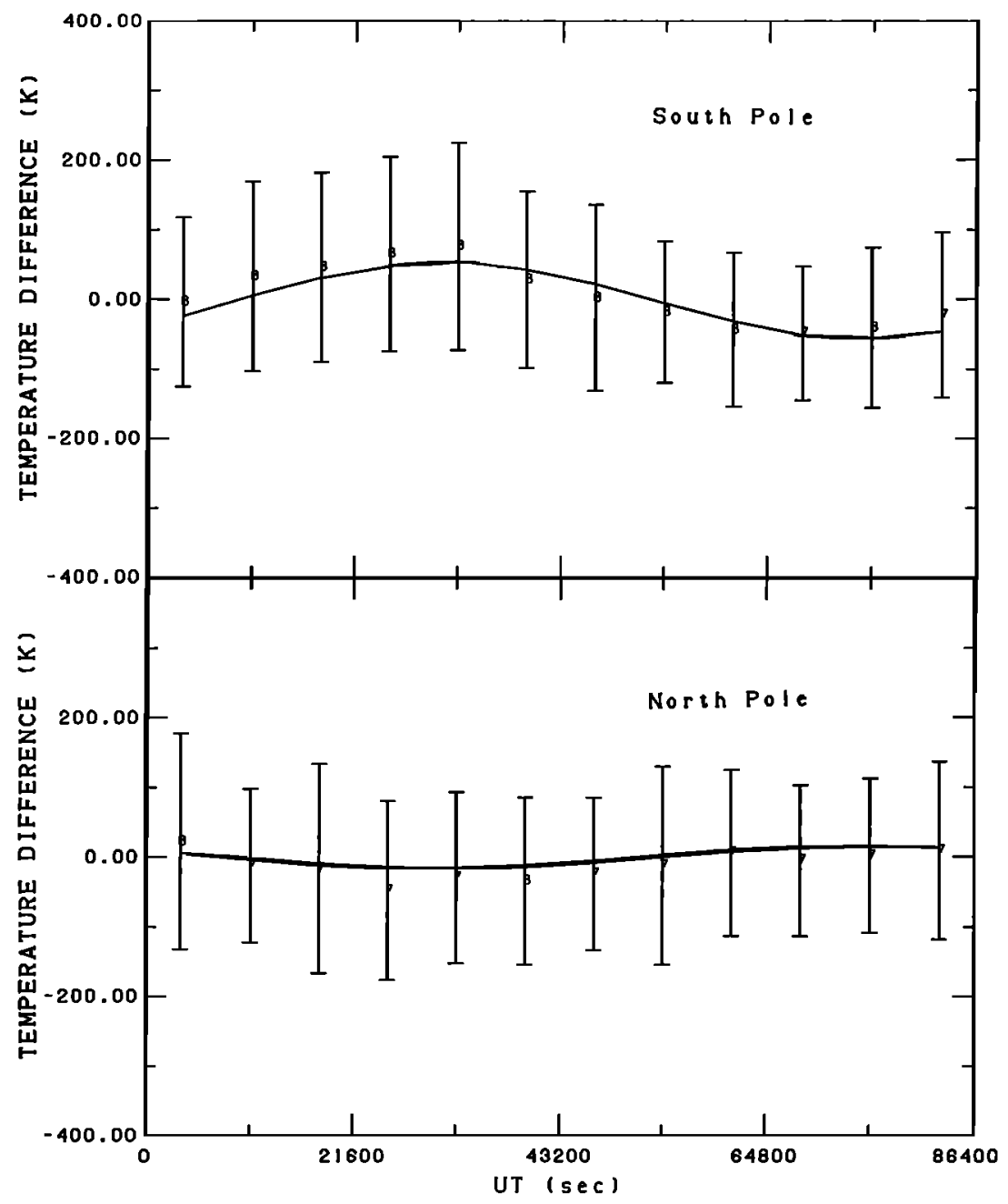

Fig. 7. Measured minus MSIS-86 model temperatures, with model universal time terms omitted, versus universal time averaged in 2-hour intervals and corresponding model predictions (connected by straight lines) during quiet magnetic conditions for latitudes greater than $70^{\circ}$ (lower panel) and less than $-70^{\circ}$ (upper panel).

corresponding data minus model predictions without the longitude terms of the model. At high latitudes the temperature enhancements near the magnetic poles are well represented by the model, including the larger effect at the south pole. OGO 6 temperature results near the magnetic poles at low and high magnetic activity were discussed by Thuillier et al. [1980].

In addition, however, the data (Figure 4) show a marked enhancement over the South Atlantic region. There are actually relatively few data points here because data had been previously eliminated [Thuillier et al., 1977a] for high instrument background caused by the hard radiation encountered at high altitudes over the South Atlantic magnetic field anomaly. While it is possible that neutral temperatures may actually be enhanced in this region, an examination of Dynamics Explorer neutral wind and temperature spectrometer (WATS) data [Spencer et al., 1981] which had good coverage over the South Atlantic did not show any evidence of this anomaly in the 300 - to $400-\mathrm{km}$ altitude range. In addition, the OGO 6 optical temperature increases sharply with altitude of the satellite to over $200 \mathrm{~K}$ above the model temperature near 800 $\mathrm{km}$. Although restriction to lower satellite altitudes does not completely eliminate this anomaly, such a marked dependence on satellite altitude is not observed outside the South Atlantic region. Thus this effect is likely an OGO 6 measurement problem.
The data minus model differences are shown as a function of latitude and local time in Figure 5. While differences are generally of the order of $20 \mathrm{~K}$, there is a significant area of low measured temperatures around local noon. As noted by Thuillier et al. [1977a] and Blamont et al. [1974], this anomaly was so severe in the original data that the apparent diurnal maximum was at night, and even after refinement these data still differ from the incoherent scatter data. Measurements in this area are difficult because of low signal levels and high background light levels, and so this noon depression may not be a real feature of the ambient atmosphere.

The data minus model differences, without the magnetic activity terms of the model, as a function of magnetic activity $(A p)$ averaged in 10 unit bins are shown in Figure 6. Also shown are the model predictions for the magnetic activity variations averaged for the data conditions. The general trends at low and high latitudes are fairly well represented by the MSIS-86 model. The observed increase in magnetic activity effects on thermospheric temperature toward high latitude, in contrast to little or no latitude dependence in drag models, was reported by Blamont and Luton [1972] and modeled by Thuillier et al. [1977a].

There is a significant temperature variation with universal time at high southern latitudes consistent with the model, as seen in Figure 7. At northern latitudes the universal time vari- 
ation is weak and out of phase with the southern polar variation, as predicted by the model and originally estimated from $\mathrm{N}_{2}$ data [Hedin et al., 1979].

\section{CónClusion}

The thermospheric temperatures measured by the FabryPerot interferometer on the OGO 6 satellite are reasonably represented by the MSIS-86 empirical model except for two anomalies, one in the South Atlantic and the other near local time noon, which are likely due to measurement problems. The OGO 6 temperature data were not used in the generation of the MSIS models, so this is an independent comparison of measured and model temperatures. Latitude gradients during solstices as well as for the yearly average are well represented by the model, as are magnetic activity and high-latitude longitudinal and universal time variations. On average, the measured temperatures are $16 \mathrm{~K}$ below the MSIS- 86 model temperatures. This agreement between temperatures measured by the satellite-borne Fabry-Periot interferometer and predicted by an empirical model is in contrast to differences of the order of $100 \mathrm{~K}$ found with ground-based optical measurements. However, outside the polar regions the satellite measurements were largely made during daytime, and the ground-based measurements during nighttime. Further detailed comparisons with ground-based measurements should shed more light on these temperature differences.

Acknowledgments. The Editor thanks F. Barlier and T. L. Killeen for their assistance in evaluating this paper.

\section{REFERENCES}

Biondi, M. A., and W. A. Feibelman, Twilight and nightglow spectral line shapes of oxygen $\lambda 6300$ and $\lambda 5577$ radiation, Planet. Space Sci. $16,431-443,1968$.

Biondi, M. A., and J. W. Meriwether, Measured response of the equatorial thermospheric temperature to geomagnetic activity and solar flux changes, Geophys. Res. Lett., 12, 267-270, 1985.

Blamont, J. E., and J. M. Luton, Geomagnetic effect on the neutral temperature of the $F$ region during the magnetic storm of September 1969, J. Geophys. Res., 77, 3534-3556, 1972.

Blamont, J. E., J. M. Luton, and J. S. Nisbet, Global temperature distributions from the OGO 6 6300- $\AA$ airglow measurements, Radio Sci., 9, 247-251, 1974.

Carru, H., M. Petit, and P. Waldteufel, On the diurnal variation of the thermopause temperature, Planet. Space Sci., 15, 944-945, 1967.

Cogger, L. L., G. J. Nelson, M. A. Biondi, R. D. Hake, Jr., and D. P. Sipler, Coincident $F$ region temperature determinations from incoherent backscatter and Doppler broadening of [O I] $6300 \AA, J$. Geophys. Res., 75, 4887-4889, 1970.

Evans, J. V., Theory and practice of ionosphere study by Thomson scatter radar, Proc. IEEE, 57, 496-530, 1969.

Feibelman, W. A., R. D. Hake, Jr., D. P. Sipler, and M. A. Biondi, Twilight and nighttime ionospheric temperatures from oxygen $\lambda 6300$ and $\lambda 5577$ spectral line profiles, J. Geophys. Res., 77, 1869 $1877,1972$.

Hays, P. B.. A. F. Nagy, and K. D. McWatters, Comparison of radar and optical temperature measurements in the $F$ region, $J$. Geophys. Res., 75, 4881-4882, 1970.

Hays, P. B., T. L. Killeen, and B. C. Kennedy, The Fabry-Perot interferometer on Dynamics Explorer, Space Sci. Instrum., 5, 395416, 1981.

Hedin, A. E., A revised thermospheric model based on mass spectrometer and incoherent scatter data: MSIS-83, J. Geophys. Res., $88,10,170-10,188,1983$.

Hedin, A. E., MSIS-86 thermospheric model, J. Geophys. Res., 92, 4649-4662, 1987.

Hedin, A. E., H. G. Mayr, C. A. Reber, N. W. Spencer, and G. R.
Carignan, Empirical model of global thermospheric temperature and composition based on data from the OGO 6 quadrupole mass spectrometer, J. Geophys. Res., 79, 215-225, 1974.

Hedin, A. E., et al., A global thermospheric model based on mass spectrometer and incoherent scatter data, MSIS $1, \mathrm{~N}_{2}$ density and lemperature, J. Geophys. Res., 82, 2139-2147, 1977.

Hedin, A. E., C. A. Reber, N. W. Spencer, H. C. Brinton, and D. C Kayser, Global model of longitude/UT variations in thermospheric composition and temperature based on mass spectrometer data, $J$. Geophys. Res., 84, 1-9, 1979.

Hernandez, G., Mid-latitude thermospheric neutral kinetic temperatures, 1, Solar, geomagnetic, and long-term effects, J. Geophys. Res., 87, 1623-1632, 1982.

Hernandez, G., Fabry-Perot Interferometers, Cambridge University Press, New York, 1986.

Hernandez, G., T. E. VanZandt, V. L. Peterson, and J. P. Turtle, Comparison of optical and incoherent scatter measurements of nighttime exospheric temperature at the magnetic equator, J. Geophys. Res., 80, 3271-3274, 1975.

Jacchia, L. G., Static diffusion models of the upper atmosphere with empirical temperature profiles, Smithson. Contrib. Astrophys., 8 , 215-222, 1965.

Jacchia, L. G., Revised static models of the thermosphere and exosphere with empirical temperature profiles, Spec. Rep. 332, Smithson. Astrophys. Obs., Cambridge, Mass., 1971.

Jacchia, L. G., Thermospheric temperature, density, and composition: New models, Spec. Rep. 375, Smithson. Astrophys. Obs., Cambridge, Mass., 1977.

McCormac, F. G., T. L. Killeen, B. Nardi, and R. W. Smith, How close are ground-based Fabry-Perot thermospheric wind and temperature measurements to exospheric values? A simulation study, Planet. Space Sci., 35, 1255-1265, 1987.

Nisbet, J. S., Neutral atmospheric temperature from incoherent scatter observations, J. Atmos. Terr. Phys., 24, 586-593, 1967.

Shepherd, G. G., Spectroscopic measurement of upper atmosphere temperature, in Temperature: Its Measurement and Control in Science and Industry, vol. 4, edited by H. H. Plumb, part 3, pp. 23132327, Instrument Society of America, Pittsburgh, Pa., 1972.

Sipler, D. P., M. A. Biondi, and R. G. Roble, F-region neutral winds and temperatures at equatorial latitudes: Measured and predicted behavior during geomagnetically quiet conditions, Planet. Space Sci., 3l, 53-66, 1983.

Spencer, N. W., H. B. Niemann, and G. R. Carignan, The neutralatmosphere temperature instrument, Radio Sci., 8, 287-296, 1973.

Spencer, N. W., L. E. Wharton, H. B. Niemann, A. E. Hedin, G. R. Carignan, and J. C. Maurer, The Dynamics Explorer wind and temperature spectrometer, Space Sci. Instrum., 5, 417-428, 1981.

Thuillier, G., J. L. Falin, and C. Wachtel, Experimental global model of the exospheric temperature based on measurements from the Fabry-Perot interferometer on board the OGO-6 satellite, $J$. Atmos. Terr. Phys., 39, 399-414, $1977 a$.

Thuillier, G., J. L. Falin, and F. Barlier, Global experimental model of the exospheric temperature using optical and incoherent scatter measurements, J. Atmos. Terr. Phys., 39, 1195-1202, 1977 b.

Thuillier, G., J. L. Falin, and F. Barlier, Magnetic activity effects on the exospheric temperatures at high latitudes, J. Atmos. Terr. Phys., 42, 653-660, 1980.

Yagi, T., and P. L. Dyson, Measurements of thermospheric temperatures at a mid-latitude station, Planet. Space Sci., 33, 203-206, 1985.

Yee, J., Non-thermal distribution of $O\left({ }^{1} D\right)$ atoms in the nighttime thermosphere, Planet. Space Sci., 36, 89-97, 1988.

A. E. Hedin, NASA Goddard Space Flight Center, Code 614, Greenbelt, MD 20771.

G. Thuillier, Service d'Aéronomie du Centre National de la Recherche Scientifique, 91371 Verrières-le-Buisson, France.

(Received December 17, 1987; revised February 26, 1988 ; accepted March 17, 1988.) 